\title{
Traditional Continuation and Modern Transformation: A Study on the Changes of Structures and Functions of Border Markets in Yunnan Province
}

\author{
Yin Jiandong \\ Yunnan Minzu University \\ Liu Weiwei \\ Yunnan Minzu University
}

The border areas of Yunnan show complex and diverse ecological environments and unique geographical locations which make their rural markets bear typically ethnic, regional and open features of cross-border exchanges. The structures and functions of the border markets are undergoing significant modern transformation with the development of market economy, rapid urbanization and construction of towns in the border areas. This paper explores how the space and time structures of the markets have been reshaped in the process of modern changes; while as the traditional economic function of the markets has been gradually weakened, a trend of increasing social and cultural functions has emerged. This factor reflects that the border markets, rural societies and ethnic cultural traditions in Yunnan are undergoing structural changes bringing about diversity in the marketing system.

\section{INTRODUCTION}

In academic research, markets are often named as "periodic markets" or "fairs" generally referring to gathering of buyers and sellers at relatively fixed locations at certain times and periods for trades and exchanges. In the vast rural areas of China, since the markets always bear functions of trading and social interaction, the markets and their related studies have been focused in the fields of history, sociology, and anthropology for a long time.

In the 1930s, the Japanese scholar Kato F. (1973) first systematically analyzed and described the regular markets and their structures and functions in rural areas of North China with Chinese local records. Later, Yang Qingkun clarified the "internal function, structure and operation" of Zouping's traditional markets through a concentrated field survey of the Cheng-Guan-Ji, Ming-Jia-Ji and Liu-Juqiao-Ji and other seven markets; and then he pointed out that in the period when China's society was about to enter the stage of industrial revolution and urbanization after Europe had done, the market reflected the changing economic structure and organization of rural areas in China (Yang, 1934). In Peasant Life of China, Fei Xiaotong analyzes the rural markets, focusing on the economic and trading role of markets in the rural community. He believes that the primary markets in the village community cannot meet the villagers' demands for social obligations, mutual reception, accommodation, mutual support, and gift exchange. Only a higher level-the intermediate market-can effectively satisfy the farmers' daily needs. 
Since the intermediate market is always located in a town, "the town is the center of exchanges between the farmers and the outside world" (Fei, 2001 :206-217). Farmers buy industrial products from the middle merchants in the town and sell the products to the acquiring specialists there. Yang Maochun (2001), in his study of the community of Taitou Village in Shandong, emphasizes the social and political functions of the markets apart from their economic and trading functions. Young's research shows that the markets not only provide the villagers public places for communicating, but also are important joints of scattered villages.

In the first half of the 20th century, a lot studies were conducted on markets in China, so was done on the social and economic condition and trade in the southwestern region of China, especially in Yunnan's frontier regions. For example, Jiang Yingliang (2009: 167-169), based on the field surveys, discusses the market trade, commodity circulation, and currency in the "Baiyi" region. Li Youyi (2014: 75-85) makes a systematic analysis of the "Han-Yi" economic relations and changes in the Nanwei Village of Lunan in Yunnan in his book "The Economy of the Han-Yi Co-Inhabited Areas" and depicts the roles and status of grass-root markets, and how they affect the local villagers. Although the chapters of these works related to the markets are relatively simple, they laid foundations for later research on trade in Yunnan's ethnic minority areas.

In the academic world outside China, American anthropologist Skinner's "market system theory" indicates that the study of China's traditional township has entered a mature stage. He published the article titled Marketing and Social Structure in Rural China in The Journal of Asia Studies in 1964 and 1965. In the article, he proposed a unique method to analyze China's grass-root society, namely the "Skinner Model." Adopting the "Central Place Theory" proposed by German geophysicist Christaller, Skinner clearly put forward that the study of the China's urban and rural economy and society is based on the structure of the markets. Skinner pointed out that based on the structure of the markets, the structure and operation of the Chinese economic system can not only be elucidated from a spatial point of view, but also the study of the structure of Chinese society can be differed from those traditional studies based on the administrative system. Though being at the lowest level in the market system, the rural market plays an extremely important role. It is not only a place for farmers to exchange goods, but also a starting point for the rural surplus products to enter a higher-level market system. The rural market is also the ending point of goods provided to the villages. Moreover, Skinner believed that "farmer's actual social area is not determined by the narrow range of his village where he lives, but by the boundary of the grass-root market area where his village belongs to" (Huang, 1986:23). Thus, Skinner's analysis on the functions of the Chinese markets has reached an unprecedented level leading to the comment that Skinner made "a whole generation of American historians believes that Chinese villages are economically and socially highly integrated with the big trading system" (Huang, 1986:23). In addition, influenced by Skinner's marketing theory, anthropologists who study China's problems are no longer constrained by small villages, but they pay more attention to the role of the markets in the social structure, expanding their research to marketing areas. When Eric R. Wolf was conducting his anthropological research in the Han Chinese society in Taiwan, he focused on the Sanxia marketing area. Since 1988, both foreign scholars such as Helen F. Siu, David Faure, Hamashima Atsutoshi, and Okayama, etc. and Chinese scholars have focused on market towns in the Pearl River Delta region, such as Xiaolan, Shawan, Shatou, Lubao and Longjiang (Liu, 1993).

In contrast, due to some complicated factors, the research on the Chinese markets by Chinese scholars remained at a low level for a long time after the establishment of the People's Republic of China. Until the 1980s and 1990s, market researches again won the attention in the field of history, sociology, and anthropology. The research orientation and research focus of history are more consistent, which focuses on the morphological structure, historical changes, like the rise and fall of the dynasties in various markets of different regions in China since the late Qing Dynasty to the Republic of China. Combined with empirical data, these historical studies launched academic discussions and theoretical dialogues among senior scholars like Skinner. For example, Bao Weimin (1998) conducted a good research 
combining empirical research and theoretical analysis on Jiangnan Town and its rise and fall at the modern times. Fan Shuzhi (2005) adopted both macroscopic and microscopic approaches to explain the development of Jiangnan from the Ming and Qing Dynasties to the Republic of China. Wang Di (1993) in his book, titled "Across the Closed World, Regional Social Research (1644-1911) in the Upper Yangtze River", applied the "Skinner's model" to analyze in detail the regional trade, city system and market network in the upper reaches of the Yangtze River in the Qing Dynasty by discussing a series of issues such as the role and function of the market, market density and activity sphere, advanced markets and urban development. Later, Wang Qingcheng made a detailed analysis of the markets and market circles in North China during the late Qing period based on the local records from dozens of counties in North China. He questioned Skinner's theory and formula on Chinese rural markets and social structure. Wang Qingcheng has made an elaborated study of the growth of regular markets in North China in the late Qing Dynasty, and put forward an innovative view that poverty was a result of the increase in the volume of trade and the number of markets, and the expansion of commodity circulation in northern rural markets in late Qing Dynasty. Moreover, Gong Guan (2001), Li Zhenghua (1998), Xu Tan (1998) and others have conducted some unique studies on North China markets, ranging from historical development and its characteristics, the transformation process and historical trends, the relationship between the railway and the town development to markets and commodity economy. The above researches fully demonstrate the important influence of the "Skinner's Model" in this field.

Compared with the historical research, researches on the markets in sociology, anthropology and other disciplines in this period were greater in number. However, a number of outstanding researches were conducted on the markets in North China and Southwest China. Among them, Lu Yilong (2012), whose research was focused on temple fairs and markets in Dingzhou, Hebei Province, drew a general conclusion on the basis of the development and prosperity of the rural market in North China that transformation and development of rural societies were brought about by the construction of modern markets of agricultural products and other products. Huan Pingqing (2005) discussed the changes of the rural markets in Dingzhou, Hebei, the differences and reasons of the market transition between China and the West, and the difficulties and trends of rural social transformation in North China. He gave an innovative viewpoint about transformation that urbanization was the only way to go out of the dilemma. In the study of the markets in ethnic areas in southwestern China, based on the ethnological and historical data, Wan Hong (2004) discussed the formation and evolution of the markets located in the southwestern ethnic areas of China. Wu Xiaoyan (2008) took Yuantong in eastern Sichuan as her research site, and adopted microscopic empirical research methods that included rural markets in the historical process of modern country construction. Based on her research in the Nuosu (Yi) region in Liangshan, Sichuan Province, Liu Shaohua (2010) pointed out that the interaction between the traditional culture of Nuosu and the market system had caused great impacts on the local social life and social changes. Zhang Yue and Wang Xiaoyan (2010) took insight into the rich cultural connotation of the markets and their ties to the entire community network through a case study of markets in a Yi community in Yunnan. Most of the above researches bear the features of facing the status quo and problems of contemporary Chinese markets from the perspective of sociology and anthropology, expanding the views and dimensions of relevant market researches.

However, though Skinner and other previous researchers on China's markets attached great importance to revealing and exploring the economic, political, and social functions of the markets, their studies were focused on traditional markets which had existed for a long time before the establishment of the People's Republic of China. They paid more attention to such issues as the historical changes of the market, the rise and fall of the relationships, and the relationship between the rural society and the transformation, but less attention was given to the functions and roles of these markets at the modern times. Thus, in these studies, we cannot learn more about the changes of the function of the contemporary Chinese markets. Moreover, from the perspective of the regional study, the markets in Northern part of China and Jiangnan regions have always been relatively prosperous with rich historical records, bearing 
clear the historical development. Therefore, the market researches done in these areas seem to be a paradigm in the field. Rural markets scattered in frontier areas, especially in the border areas of Yunnan, which are closely related to the production and livelihood of ethnic minorities, have got insufficient attention. Besides, researches conducted in these regions are relevantly ignored. What is the space-time structure of markets in Yunnan's border areas? What role does it play? Are the functions of markets which have been pointed out by modern researchers including Skinner still continue being played in border areas of Yunnan? Have any changes taken place in the structure and function of those markets that previous researchers have not noticed? To answer these questions, this paper attempts to use macroscopic approach based on historical literature and fieldwork to explore the continuation of the traditional structures and functions of the border markets in Yunnan province, and to analyze the transformation of those border markets in the background of the contemporary market economy and urbanization process.

\section{Exchange and Contact: Continuation of Traditional Structures and Functions of Markets in Yunnan}

Yunnan is a province with the largest number of ethnic minority groups in China. The complex and diverse geography and ecological environment make this area inhabited by several ethnic groups, but each ethnic group relevantly lives together. Therefore, the scattered rural markets are not only an economic or cultural coordinate in the geographical space, but they also play important social and cultural roles. In particular, markets can be regarded as special areas that extend across national borders and ethnic groups due to their special geographical location. Since the appearance of markets in the Yunnan border areas, they have not only enriched the residents' material and cultural life because of their unique function of radiation and acculturation, but to some extent have also formed "marketing cultural circle" around the boundary markets, which has profoundly affected the life style and even cultural traditions of the residents in border areas.

\section{Market Period: Continuation of Traditional Space-Time Structure}

In the historical process, on the one hand, the development of markets in ethnic minority areas in Yunnan has been affected by many factors such as the local natural environment, folk traditions, livelihoods, and the pace of life; on the other hand, they have also been deeply influenced by the commercial culture of Han people. In terms of the time system, it is similar to the Inland China based on "regularity", and some "regular markets" form a stable cyclic structure with a fixed time rhythm in a certain geographical area, which has continued to today.

In general, there are mainly five types of the time systems for the trade markets in multi-ethnic areas on borders: (1) continuing to use local marketing traditional system of 12 Earthly Branches; (2) adopting the old calendar or the lunar system; (3) adopting the calendar system; (4) adopting the week system; and (5) daily markets (Wan, 2006). In addition, in some areas, there are some markets without fixed time period.

Generally speaking, the local traditional marketing system of 12 Earthly Branches (represented by 12 animals) is adopted in some remote areas where transportation is not convenient. For example, in Chengguan Town of Yuanyang County, Honghe Hani and Yi Autonomous Prefecture in Yunnan Province, there is a market for every dragon day, rat day, and monkey day; in Niujiaozhai Town, there is a market for every dog day, tiger day, and horse day; in Dunhou Town, there is a market for every dragon day, monkey day and rat day (Niu, 2000:161-162). Markets are on every mouse day and horse day at Jinhe Town of Jinping Miao and Yao and Dai Prefecture County. Markets are on monkey days and tiger days in the town of Mengla (Niu, 2000:161-162). In these regions with the 12 earthly branches systems, the time system, rhythm, and folklore tradition differ with those in other regions. The names of the markets such as "Horse Street", "Cattle Street" and "Chicken Street" actually reflect the 12 earthly branches of animals. The reasons for its formation are entirely related to the arrangements for agricultural production in different areas, which is to avoid taking up too much production time and to exchange goods conveniently. 
Therefore, the intervals of markets are neither too long, nor too short, and are of roughly 5 to 7 days. Meanwhile, the periods of markets are overlapped so that people in different regions can exchange with each other and adjust shortages (Ma, 1987). For example, according to the historical data, markets at Longchuan in Dehong Prefecture have transactions on a five-day period. Villagers go to markets intricately. The market period calculated by the folk is that the fifth day is the market day after four-day rest, except that at the chieftain's residential place, the marketing day is on the same day. During the Cultural Revolution, marketing for seven days or ten days was generally implemented, which was on the same day for the whole county. It was not until 1979 that it resumed marketing after five days. At present, the marketing time at townships is set by the overall planning of the county, and the marketing at villages is arranged alternatively within the township (Wang, 2012). Those who adopt the lunar calendar system are more often Han people living in agricultural areas, though some ethnic minorities also accept the lunar calendar system. Markets are set on every fifth to tenth day or on every third, sixth and ninth day, or every fourth or ninth day, or every first, fourth or seventh day, etc. of each month according to the lunar calendar to form a periodic rotation in the region.

"Weekly" and "Gregorian calendar" periods marketing are more frequently adopted around the towns in the border areas. For the "weekly" system, every Thursday, Sunday, Wednesday, or Saturday can be the marketing day. In the "Gregorian calendar system", marketing days are on the 2nd, 5th, and 9th day of each month, or on the 3rd, 6th, and 9th day of the month, or on the even dates of the month, etc. Generally, the scope where the weekly calendar system is adopted is relatively narrow, which is mostly confined to the inner areas of cities and towns. The scope where the calendar system is adopted is relatively large, which appears in some higher urbanized places where the Gregorian calendar system has long been established and commodities are relatively developed. In areas where different ethnic groups live together, there are some cases where different time systems are used in a mixed way.

As for the daily marketing, it is often located in areas with high population density, rich products, convenient transportation, and high commercialization. In addition, in some areas of raw material production or mining area, it is easy to manage daily marketing, or even large markets at some fixed interval. The reason why such regions haven't formed fixed markets is that these regions are distributed by ethnic groups located in remote mountainous areas. However, handicraftsmen and traders go to the villages from time to time to exchange daily necessities and food.

Thus, the contemporary markets in Yunnan border areas have a more complex time-space structure than those in the Inland China. The existing market network systems are actually determined by the spatial and temporal distribution patterns of the markets, which reflect the overall situation of the markets in border areas in Yunnan to some extent. At the same time, the spatial arrangement and temporal system of various markets are formed in the course of long-term historical development, which are matched with their corresponding regions and populations. Thus, such spatial arrangement and temporal system on one hand, reflect the close relationship between the complicated humanistic and geographical environment of the border areas in Yunnan, and the diversity of cultural traditions, and on the other hand, it also reflects their traditional agriculture and handicraft production, trading circles, and the interaction between settlement social relations and regional cultural identity in the long run. Above all, the continuation of historical development and distinctive regional cultural characteristics are embodied in the time-space structure of the markets.

\section{Market Exchange: Continuation of Traditional Economic Functions}

As a primary form and place of commodity exchange, rural market has lasted for thousands of years. As Braudel points out, "Exchanging has existed from the beginning of the human beings, and the historical research on the markets should be extended as far as possible. All the markets can testify that: a number of backward trading venues which are rare are at the first level, which are ancient species left before the Great Flood. The primary market is at the first stage of the economic ladder, which is the best form of exchange that is most direct, transparent, and supervised. 'First-hand' transactions are in the 
primary market. On the spot, the deal is made." (Braudel, 1993: 228) It can be said that the regular market determines the rhythm and pace of rural life. The market is a product of the peasant society, the peasant culture, and the peasant economy (Braudel, 1993: 103-105).

Commodity exchange in Yunnan's border areas has a long history, and it can even be traced back to the pre-Qin period. However, the real markets flourished in the Ming and Qing Dynasties, many of which still exist today. From the Qing Dynasty, the Republic of China to the present, the border markets have changed their forms from barter, "walking villages to exchange" and temporary markets along the roads, to the fixed market trading venues and market periods for exchanges, and even to rich commodity transactions like the daily marketing in big cities. Their development is similar to the evolution of the market trade in other parts of China, and has undergone a process of development from a low-level, non-conventional market to an advanced fixed one. This historical change has not only been recorded in the literature and data, but also has left a deep imprint in the historical memory and daily life of the ethnic people.

Markets in the Yunnan Border areas have been a material space with the main function of commodity exchange from past to present. It is characterized by the exchange of its surplus products, agricultural and sideline products, handicraft products, and special products among different ethnic groups in different trading circles from mature rice farming and fishery products in the flatland to dry land crops and prey in mountainous areas; from the nomadic livestock and dairy farming products in the high mountains of western Yunnan to the local special products in the slash-and-burn mountainous regions of eastern and southern Yunnan; from subtropical fruits and vegetables of southernmost Yunnan to highland barley and blankets in the high mountain areas in northwestern Yunnan; from agricultural and sideline crops, poultry, livestock and regional specialties such as tea and salt in the Han people area to the ethnic handicraft textiles, handicrafts, medicinal materials, and mountainous property and other materials specially produced and collected by ethnic minorities. As long as there are surplus products, they are sent to the market instantly. The scene is almost same as the markets in Zouping in Shandong Province written by Yang Qingyi in the 1930s. Today, the markets in the border areas in Yunnan are still the places for people living in the neighboring areas, especially for those cross-border peoples to sell their own primary agricultural and sideline products, handicrafts, and ethnic specialty products.

Moreover, the markets in border areas of Yunnan, as Fei Xiaotong (2001:206) said, "are the main places where every peasant gets his daily necessities that he does not produce." Although almost every village in the border area of Yunnan now has its own grocery store, some daily necessities such as salt and candies can be bought in the village, but more items needed by families still need to be got at the time of marketing in the town. For example, fresh pork, beef, and lamb are not available in the village canteens. They can only be bought at markets. A lot of bulk oil and rice supplies or household appliances, such as rice cookers and electric teapots, or household items, such as hoe, sickle or other agricultural tools or tables and chairs, as well as clothes are available at markets.

In addition, compared with the urban and rural markets depicted by C. K. Yang, Fei Xiaotong and Skinner in China before the middle of the last century, a unique trading way in the Yunnan border regions has continued: cross-border trading. Yunnan Province is bordered by Vietnam, Laos, and Myanmar. It is common for peoples (from different ethnic groups) to go across the national borders. Therefore, the cross-border markets have emerged. In the early stage, the bordering markets are only a form of transaction developed spontaneously by the people on both sides of the national borders. Its trading location and time are modeled on the traditional markets and set dates. In the mid-1980s, the cross-border markets were gradually governed by the government's border trade management, allowing Chinese border residents to trade within the limit of 100 yuan per person per day. Since then, with the increase of trade amount in the border areas, the limit of borderline transactions has gradually increased to 8,000 yuan today. Also, the types of goods for trade have also evolved from agricultural and sideline products to hardware, household appliances, building materials, daily necessities and sanitary wares, etc. As a result, the mutual exchanges on borders have also developed into a modern trade service industry which 
originally aimed at improving the bordering people's life by bartering. For example, the mutual exchanges in the border areas of China and Vietnam, people on the border of the two countries usually sell their unique native products in the markets and then buy some production and living goods home. Even if it is not the marketing day, the phenomenon that Vietnamese go crossing the border to exchange goods is still common (Zhang and $\mathrm{Gu}, 2012$ ). Another example is in Ruili City on the border between China and Myanmar. Statistics show that the number of people participating in the border-marketing exchanges has reached millions each year. The types of mutual-traded goods have also increased from dozens in the early 1980s to the thousands at present. In the case of buyers and sellers, Burmese sold oversea goods while Chinese bought them in the early 1980s. However, the situation has developed to level off for both sell and buying (He, 2011: 252). In the areas like Hekou, Mengding, Mohan, Wanding, Daluo, etc., where there is a history for border trading, cross-border trade is an important source of income for local people. Even in the border areas where no ports are set, villagers and businessman at home and abroad can enter each other's markets "conveniently" to do transactions. Such "peaceful cross-border" trading model is a special way of economic exchange formed by the residents in the historical development.

Skinner once predicted that China's rural markets would gradually disappear at the end of the 20th century with the development of modern society and economy. However, the markets in the border areas of Yunnan remain as an indispensable part of ethnic villagers' life. Comparing with the urban and rural societies in the Inland China, which have a relatively complete modern market system, the complicated geographical environment, the undeveloped economic foundation and the less urbanization in Yunnan's border areas have restricted the development of the social economy and the needs of people. Exchanges of necessities and commodities must be realized in rural markets. The small rural markets spontaneously formed in the past still play a role as an economic supplement to production and life of various ethnic groups. In this sense, "ethnic economic exchanges are an important form of the ethnic economy. Economic exchanges are the first need for the survival of an ethnic group and are the most important contacts" (Jin, 2007: 184). For all ethnic groups trading in the markets, the choices of commodities and transaction ways will obviously be highlighted before their cultures and ethnic consciousness (Zhang and Wang, 2010).

\section{Exchanging in Market: Continuation of Traditional Social and Cultural Functions}

In the rural society, a market is undoubtedly a public space, which reflects a certain existing public nature within the society, as well as the relatively fixed social association forms and interpersonal structures. As early as the 1960s, Skinner (1998) made it clear that since the market structure bears all the characteristics of the Chinese agricultural society, market is a unique social system in traditional China. Later, Fairbank (2008: 26-28) further re-expressed the concept of "primary market" which was defined by Skinner as "market society", arguing that it is "the combination of an economic unit and a social world". "In normal situation, the peasants' lives are not confined to a village, but to a large number of villages that form a market community." Thus, market bears contact function since its born which links goods and people, people and people. Market is one of the most dynamic places in rural society.

Yunnan Province is bordered on Myanmar, Laos and Vietnam. The border markets in Yunnan have always been important places for many ethnic groups at home and abroad. First, the markets in such areas present peoples' transnational flows, which radiate the neighboring nations. Secondly, the ethnic minorities living in the border areas are mostly multinational, whose kinship, geographical relationships, etc., can be fully reflected in the markets where different nationalities gather. Economic activities weaken the boundaries of national differences. Language, commodity, and transaction are the main focus in the markets, while ethnic composition and consciousness, etc., are relegated to secondary positions. The ethnic symbols of the peoples in the markets are no longer the focus. For example, a researcher once did his research in the northwestern village of Ma Andi Township in Jinping County on the Sino-Vietnamese border. He found that the common languages in the local market were Hani, Chinese, and Hmong. Simple words such as sugar, cigarettes, alcohol, and needs, can be helpful in the transaction. People who can't 
speak such marketing languages have to adopt gestures to communicate. In the northwestern market, many vendors can speak several simple languages for trade ( $\mathrm{Li}, 2011)$. Moreover, in the markets in Xishuangbanna, which is Dai area, people can speak both Han language and Dai language in marketing. Besides this, most Dai people there can speak other languages of neighboring ethnic groups. Bulang people have long-term economic and cultural exchanges with Dai people, who are deeply influenced by Dai's culture. Although Bulang people have their own language, they expressed numbers in Dai language except those from one to ten. The majority of Han residents living in the Wuyi "street" can speak Dai, Hani, and Yao language (Wan, 2006: 83), which are not uncommon in other markets along the Yunnan border.

What should be stressed is that in the markets, contacts and exchanges based on geopolitical and kinship relations often constitute the most important "relationship" in the marketing area, which generally exists before the exchanges relationship in the markets. For example, in the traditional culture of the Jingpo people, it is extremely common to determine the relatives of the two sides through ethnic origins. The kinship is often expressed through a "practical way" in the market, such as drinking after meeting in the market, buying goods from relatives or selling goods to their relatives cheaply or even for free. These seemingly contradictory marketing rules continually adjust family obligations in specific market areas. Bourdieu pointed out: "From a practical point of view, farmers' merchants strive to act in accordance with the rules and explain the rules according to their needs. All the strategies they have adopted remind us that the various phenomena, especially the classification of kinships, have a purely symbolic but still tangible effect" (Bourdieu, 2003:269). Thus, what behind the market exchange and communicative activities is the continuous consolidation and development of cross-border ethnic relations in this spatial structure.

In recent years, with the socialization of production, life, and contact, the needs for information, communication, and leisure have become increasingly diverse, and the social space for farmers in border areas has been continuously expanded. However, in many places, market is still a node in people's trade, entertainment and communication networks. Many people are still regarding marketing as their own world of life. Just as what depicted by Fei Xiaotong and Yang Maochunin in the 30s and 40s of the last century, in the inland markets, people get influenced by local social and cultural traditions, meanwhile they connect their lives with wider outside world by marketing, gaining information there and going out of the village even into the cities. Thus, markets in Yunnan's border areas are not only the fields of exchanging goods; they always provide space for people to socialize. Trading, gathering and communicating in the markets create a public space for the local society, which plays an important role in economic and trade exchanges, cultural exchanges, relationship adjustment and social integration.

\section{Change and Integration: the Modern Transformation of the Structures and Functions of Markets on Yunnan Border}

Although the markets in Yunnan's border areas have been following their traditional trend of development for a long time, they take up a center position in the daily economic and socio-cultural life of the rural societies. However, what cannot be overlooked is that, with the rapid development of the urbanization and social transformation, not only have a series of changes in the structure of time and space in the markets in Yunnan's border areas taken place since this century, but also the center role that the markets on border have played are gradually weakening. At the same time, because the dual relationship between urban and rural societies in China still exists in the border areas of Yunnan, which still has a huge impact, the process of urbanization and socio-cultural transformation have not immediately brought about the modernization of urban and rural life in Yunnan's border areas. On the contrary, the different cultures of the urban and rural societies encounter in the markets. Therefore, the markets function as a social and cultural hub between urban and rural areas; it is becoming more and more prominent, and will be bound to exist for a long time in future. 


\section{Reshaping Market's Space-Time Structure}

Compared with the traditional markets, the most obvious change in contemporary markets in Yunnan border areas lies in their space-time structure, which reflects in the reintegration of the markets and their marketing period systems. In the 1950s and 1970s after the founding of the People's Republic of China, with the establishment of the planned economy system, the state incorporated market trade into the planning system, and the policy on the primary market was adjusted several times, which aimed at controlling the markets more strictly or even eliminating free markets. Until the early $1980 \mathrm{~s}$, the once banned market trade was gradually restored. During this period, some traditional fairs and markets in Yunnan's border areas, because of their being closed for many years and changes in the population and society in the border areas, could no longer be able to restore the vigorous scenes of good old days and disappeared silently in the history. With the implementation of the reform of the market economy in the 1980 s, the Yunnan border areas began their transition from a "traditional agricultural society" to a "modern industrial society" and entered a period of rapid economic development. In particular, after the implementation of the strategy for the development of western China, a large number of transportation infrastructures such as highways, secondary roads and rural roads have been built and renewed on a large scale in the border areas, which has greatly promoted the development of local urbanization. Small and medium-sized new towns have sprung up in the border areas. Furthermore, some traditional markets either faded or disappeared due to geographical reasons, or because they had completely lost the time-space attributes of the traditional ones and transformed into the "modern trading centers" as called by Skinner. At the same time, due to the emergence of a large number of small and medium-sized towns in the border areas, a new batch of regular markets has emerged in these towns and their surrounding areas.

It needs to be pointed out that, whether it is a continuation of history or new birth of regular markets on border, the time systems of the field periods have also changed with the time. As mentioned above, there are about five types of the Yunnan Border Fairs: the Chinese Zodiac system, the lunar calendar system, the Gregorian calendar system, the weekly marketing system, and the daily marketing system. Since the new century began, the Chinese Zodiac system and the lunar calendar system have gradually experienced decrease in their usage. In some cities and their suburban areas, the Gregorian calendar and the weekly marketing system have been adopted more extensively. In some highly-commercial towns, the markets have gradually developed into a daily marketing system. It can be seen from all the four systems that the time period of marketing is becoming shorter and shorter. This trend has met the standard of Skinner's "modern trading center". Thus, the last type of the market system does no longer belong to traditional ones.

In addition, the village as a center of rural society again has also profoundly demonstrated the changes in the temporal and spatial structure of Yunnan's border market. Researches on space have proposed two ideal states: formal and informal space. For the formal space, the power is mainly derived from external administrative forces, while the informal space gets it power from the traditions, habits, and demands of the village. The formation of the latter one and the various activities in the village are determined by the local knowledge and the rational choice of the survival of the villagers, which bear a strong folk tune (Cao, 2005). Therefore, villages with government administrative power obviously belong to the formal public space; the markets formation constrained by the environment of the villages belongs to an informal space. In recent years, the state's strategies of modernization and reconstruction of rural society, such as "beautiful rural construction" and "new rural construction", have mainly focused on building settlements centered on villages and defining space of public services. Such strategies make the resources of configuration and power continue to flow to the villages in the specific space-time relationships, which partially replaces some functions of markets, leading to changes in the original market spatial behavior and the relationship of market components to some extent. 


\section{Fading of the Role of the Market as Economic Hub}

Market is a place to exchange commodities, and its economic regulations and rules have been determined by the village itself as well as by the construction of the country in different historical periods. As mentioned above, in the first 30 years after the establishment of People's Republic of China, due to the economic policies of unified purchasing and marketing and the People's Commune System, the trade of the market was greatly affected and tended to wither. It's not until the 1980s when China's Reform and Opening-up period came and the market entered a new stage of historical development and returned to the daily life of farmers with policies to develop trade in the market and the acquisition of farmers' economic autonomy. In recent years, with the continuous advancement of the market economy led by the government, farmers' social life has undergone great changes. The current economic activities of farmers in the market are obviously no longer covered by the traditional "natural economy". In the process of modernity, not only has the structure and function of the market changed quietly, but also the relationship between farmers and markets has changed, which needs to be re-examined.

As far as the border areas of Yunnan province are concerned, with the improvement of traffic conditions and the rapid advancement of urbanization, the most obvious change is that market as an economic hub has been gradually weakened in people's production and life. Changes are particularly prominent in some areas which used to rely heavily on markets. For example, in the Gongshan Dulong Nationality Autonomous County of Nujiang Prefecture in Yunnan Province, there are five township markets which are located at Cikai Town, Bingzhongluo Town, Pengdang Township, Puladi Township, and Dulongjiang Township. In the past, since these areas were really remote in high mountains and deep valleys, the transportation to these areas was inconvenient and dangerous. Therefore, the local people of the Dulong, the $\mathrm{Nu}$, and the Lisuall used to depend on the nearby markets to make a living for a long time. Particularly, the area centered on the markets of Dulongjiang Township, and the traffic to the outside world was extremely inconvenient; and the local people were deeply dependent on the markets to handle their economic activities. With the completion of the Dulongjiang road in September 1999, the history of no roads to the last ethnic community among the 56 ethnic minorities was ended. By December 2014, the completion of the Dulongjiang road reconstruction project completely ended the history when vehicles could not pass from November to May because of snow blocking all the roads in the mountain. With the change of traffic conditions, ethic people are now able to get to Gongshan County quickly for their economic activities. The old market's central position in production and life has been gradually replaced by the bigger markets in county where more goods are offered. Another example is the Awa Mountain area, which is located at Ximeng Wa Autonomous County in the west of Puer City in the southwest of Yunnan Province. After the county government moved from Ximeng Town to Mengsuo Town in 2000, the urbanization construction was pushed forward rapidly. A modern city has been built quickly in the last ten years. In the past, people of the Wa and Lahu who used to trade in open-air markets around Mengsuo Town, Mengka Town, and Lisuo Township now more and more frequently go shopping in the modern supermarkets of the Ximeng County. They are becoming more and more accustomed to selling their agricultural products and livestock in the urban markets for a better price.

From the perspective of the society, the economic activities of the villagers in the border areas have increasingly centered on cities. Villagers' contact with the outside world is not necessarily by "administrative hierarchy system" or "market hierarchy system." However, they can communicate with external society directly through some distributed network systems. They make contact with each level of the markets directly and participate in any level of the market system by products. In fact, such changes have already appeared in North China. Lu Yilong (2012) completed an investigation in Dingxian, Hebei Province. He suggested that "the rural marketing centers have been moved to a centered city of the region and even farther away, and the markets in towns were no longer important cargo distribution centers." Huan Pingqing (2016) put forward that "in county Ding, Hebei Province, market was no longer a center for distributing agricultural products or a place for surplus goods, but to a large extent it had become a mobile market where the external goods are sold to rural areas." 
The modernization of transportation facilities and the rapid development of small and medium-sized cities are making the economy in all ethnic communities on the border less dependent on the local markets. With the popularization of information and communication networks, the traditional economic functions of the markets have been continuously weakening. So far, all the villages in Yunnan province have access to electricity, and have been widely covered by television signals. Furthermore, almost every villager who has received primary school education does have a cell phone. Surfing on the internet, communicating with WeChat, and even paying bills online are common. National and local policies, regulations, and service information used to be learned only in the markets, but now can be gained instantly from news on TV and cell phones. The fees that used to be paid in the towns can be paid online now. Thus, to some extent, information resources, cultural resources, and even administrative resources which were only got in the markets in the past can be gained through information network now. Although markets are still the nodes of transactions and contacts, the farmers' vision has now surpassed the boundaries of traditional markets. They can selectively participate in market activities rather than accept and adapt passively as they did in the past. It can be expected that the role of the market as an economic hub and a resource allocation center will be increasingly affected by the development of information network technology which has penetrated the rural society in China.

\section{Constantly Enhancing the Social and Cultural Functions of the Market}

There has always been a fallacy on the modern transformation of the functions of the border markets in Yunnan. As the traditional economic function of the market and its economic center role are gradually weakening, its social and cultural functions are constantly increasing. It is playing an increasingly more and more important role in social interaction and cultural recreation.

First of all, as mentioned above, the modernization of transportation and the rapid advancement of urbanization in Yunnan have brought about tremendous social and economic development in the border areas. At the same time, cities' influence and radiation functions have increased, especially in cultural production and communication, ranging from popular culture to popular fashion which are produced in the cities and then spread to the countryside. In this process, despite the fact that the dual division of identity and treatment between urban and rural areas after the Reform and Opening-up has been eliminated, the gap between urban and rural areas in social interaction and lifestyle still exists because of historical influence. Thus, markets have always played an important role in the rural society, both in social interaction and cultural recreation. Urban culture and lifestyle which are symbols of modernity will radiate in towns which are relatively densely populated with a high degree of mobility. Such urban culture and lifestyle will reach its peak during the marketing periods. Moreover, due to China's once boom of "small towns" in the 1980's and 1990's, and the flourishing prosperity of markets on Yunnan's borders, almost all the townships on border that rely on the markets have unprecedentedly well developed. It can be expected that urbanization is still one of the most important social processes in China for a period of time in the future. The function of the markets on Yunnan border as social and cultural hubs between urban and rural areas will exist for a long time ahead.

Secondly, from the view of the village, as more and more young and middle-aged villagers in the border villages flood into nearby counties, or prefecture cities far away, or even provincial capitals, those remained in the village are elderly people, women and children. The growing hollowing of the village population has made it difficult for villagers to engage in social interaction that used to be normal. At the same time, traditional village entertainment, such as visiting friends, playing cards, and play games on plazas, have gradually disappeared with the loss of the population. Thus, the markets have become the most important communicative and entertaining places for the remaining villagers, and activities at markets also become the most important social communication and cultural recreation. Even if they have nothing to buy or sell, the villagers who stay in the village are eagerly looking forward to going to the market during the marketing day so that they can chat more with villagers who come from other villages in the markets, or get together to sing folk songs, listen to the local folk songs, and watch drama 
performances to kill time when the family members are out and to enjoy the leisure time in ways not available in the village. Therefore, we can often see such scenes in the markets: energetic middle-aged and young men and women come and go or chat with each other and the elderly play cards or chess, smoke and sunbathe. For most of the remained ones, "arena" has become an indispensable part of their lives. Skinner (1998:49-50) said in the 20th century: "The standard marketing community is the relevant context of organized recreation for the peasantry. Standard and higher level markets constitute the arena of professional storytellers, theatrical troupes, blind singers, purveyors of games of chance, boxers, jugglers, performing machine sellers and magicians. Such professionals are notably absent not only from villages but in the usual case from minor markets as well. Just as market day brings relief from the tedium of rural life through the provision of recreational opportunities, so the temple fair affords the high point in the villagers' recreational year."

In addition, the villagers who are working outside have difficulty in integrating into the city life and becoming residents in the city, even if they have been working in the city for a long time because of the urban-rural dual household registration system and the gap between urban and rural areas in terms of social security such as education, medical care and pensions, as well as the unstable factors such as housing and work. Such gap cannot be eliminated immediately. However, because they have worked in the cities for a long time, they have been familiar and accustomed to the social interaction, fashion and lifestyle in the cities. When they decide to return to the countryside, they are reluctant to go back directly to the villages, and they are more willing to make a living in towns that are closer to urban social and cultural style. Even those young and middle-aged labors who return to their villages for a break are not accustomed to the relatively simple and rural lifestyle. On the contrary, they feel more comfortable in town, and they are more willing to go shopping there to seek spiritual comfort. To some extent, the markets have become places where people, especially the young ones get together, entertain, communicate and hang out. However, the people in the markets are not passively integrated into the market operation system. They will shape the markets as suitable fields based on their own cultural habits, the geographical and temporal characteristics to carry out various social activities.

Above all, the ever-increasing social and cultural functions of Yunnan border markets and their impacts on local societies have surpassed economic significance. The original social interaction model was largely governed by kinship networks, ethnic cultural traditions, and the state political system. However, with the participation of new markets and the growth of non-government markets, the above-mentioned dominance was changed and the traditional power and authority, interests and rules, relations and order structure were fundamentally shaken. Meanwhile, the social, cultural and entertainment functions of markets have been unprecedentedly released, which contribute to the conversion of the original functions and structures of the markets. In addition, the increasing social and cultural functions of the markets are also changing and shaping all aspects of people's daily lives, such as exchange mode and the way of communication, which even affect people's social concepts and economic concepts. Markets also affect people's professional ethics, values, fashion style, desires, sexual relations and imagination (Yuan, 2017), which reflects the fact that the modern changes are taking place in traditional cultures behind the markets.

\section{DISCUSSION AND CONCLUSION}

The current markets on the border of Yunnan province are undergoing a modern transformation; , their economic functions are gradually weakening while social and cultural functions are enhanced; and such transformation will continue for quite long in the future. What does this functional transformation mean for the markets in the border areas? Skinner (1998:48) pointed out that the market not only provides trading places for goods produced in the marketing community, but also constitutes a hub in the social structure of this community. Loads of economic interaction and intensive cultural interaction are proceeding in the area of the standard market. Undoubtedly, the grass-roots market theory provides us

International Journal of Business Anthropology Vol. 8(2) 2019101 
with a very effective analytical tool for understanding the border markets in Yunnan Province. The tool can be adopted to examine the structures and functions, and historical development of the markets in border areas. However, what should be stressed is that Skinner pays more attention to the "economic" activities in the market system. He believes other factors are the derivatives of economic rational behaviors. Meanwhile, because of the limitations of the times and the environment, Skinner was obviously unable to predict the trend of the development of the markets in Yunnan border areas, especially the modern transformation of the market function and their consequences. So far, the modern transformation of the border markets in Yunnan is ongoing. It clearly shows a series of structural contradictions in the process of social development. Therefore, this paper attempts to make use of the functionalist concepts of "manifest and latent function" to make an analysis of this problem.

According to Merton, the so-called manifest function refers to "the function that contributes to systematic adaption or adjustment, whose objective consequence is the recognition and expectation of participants" (Merton, 2006:153). The latent function refers to the "function that doesn't contribute to systematic adaption or adjustment, whose objective consequence is not the recognition and expectation of participants" (Merton, 2006:153, 174). When Merton (2006:174) put forward the concept of latent functions, he also clearly realized that "the prominent contribution of sociologists lies in the unexpected postulate of social activities where latent function are involved and the expected postulate where manifest function lies in." From the definition of Merton and the expectations of the researchers, we believe that the modern transformation of the border market in Yunnan is increasingly showing two important consequences.

First, from the perspective of "significant function", the increasingly prominent social and cultural functions of the markets as hubs not only promote the deep excavation of tourism resources in the border areas, but also drive the upsurge of cultural tourism. With the development of rural tourism, markets are recognized and accepted by people as resources of cultural tourism. Particularly, the markets in the border areas maintain their "original ethnic ecology". Markets are the stages for folk cultural performances. The border areas of Yunnan Province have rich resources of cultural tourism. For instance, the ethnic people's festivals, such as the "Kuoshi Festival" of the Lisu people, the "Torch Festival" of the Yi people, the "Gexu Festival" of the Zhuang, the "Huashan Festival" of the Miao people, the "Panwang Festival" of the Yao people, and the "Dong Songkran Festival" of the Dai people, have been recorded in local county gazetteers since the Ming and Qing dynasties. During these traditional festivals, villagers used to kill pigs and slaughter sheep, set campfires, and sing and dance in different ways to celebrate the festivals, which showed their unique ethnic cultures. However, with the market economy sweeping through the villages in late 1990s and villagers leaving to work in cities or towns, the village culture has been declining. Even if on the festive day, marketing day can't be as prosperous as it used to be. However, many marketing towns in the border areas have become socio-cultural hubs today, and most of the traditional festival activities held in the villages in the past have been completely moved into these towns. As time goes, even though the function of traditional festivals to satisfy gods and to entertain the people has not changed much, the needs for food, clothing, supplies, and other services during the festivals have turned marketing to be an essential part of the festivals. In some tourist hotspots with rich ethnic cultures and with convenient transportation, native culture is closely integrated into rural market tourism and has become the attractive logo for local culture. On the whole, border marketing as tourism resource is gradually becoming a new trend for cultural tourism industry in Yunnan, which undoubtedly offers a new perspective on the modern transformation of traditional ethnic culture.

Secondly, from the perspective of "potential function", in the process of the modern transformation of the economic and cultural functions, a series of unexpected social problems have occurred in the markets in the border areas and have increasingly become prominent. For instance, porn, gambling and drug phenomena are particularly prominent. The Yunnan border markets are not only the important places for goods and social exchanges as well as the cultural recreation which the local villagers enjoy, but also the gathering places for the people who are from the neighbor countries. With the coming and going of 
people from foreign countries, businessmen, tourists, and other kinds of persons, the markets have a population of high mobility and complexity. Moreover, affected by the external environment, people in these areas bear less legal ideas. Loads of smuggled goods such as cigarettes and cosmetics, porno publications are often sold in the markets; porno performances are also occasionally offered in the remote districts. Gambling by cards or machines has become common in teahouses, plazas, or in open space. The worst thing is that the number of drug users and drug traffickers depending on drugs from abroad is increasing in the border towns. Some markets even become the hardest-hit areas where drugs and AIDS are rampant. In addition, the markets which are lack of self-regulation and integration capabilities due to their remote location have become distribution centers for fake and shoddy products. Sham marketing and fraud activities also occur in the markets. The socio-cultural managements of the markets are becoming more and more difficult. In all, what have been mentioned above reflects that the functions of the border markets in Yunnan province have undergone an extremely complex transformation in the modern era and are facing unprecedented opportunities and challenges.

\section{ACKNOWLEDGE}

Yin Jiandong is a professor and Liu Weiwei is a lecturer at School of Humanities of Yunnan Minzu University. Address for correspondence: 2929 Yuehua Road, Chenggong district, Kunming,650500, P. R.China. E-mail: jiandongyin1965@163.com

\section{REFERENCES}

Bao W. M. 1998. Jiangnan town and its modern destiny (1840-1949). Beijing: The Knowledge Publishing House.

Braudel F. 1993. Civilisation materielleeconomieet capitalism XVe-XVIIIe siècle, tome 2 (translated by Shi K. Q.). Beijing: Joint Publishing.

Bourdieu P. 2003. Le senspratique (translated by Jiang Z.H.).Nanjing: Yilin Press.

Cao H. L. 2005."Public space in rural changes: a study on reconstruction of the village order- taking Yao village in North Jiangsu." China Rural Survey 6:61-73.

Fan S. Z. 2005. Jiangnan town: traditional transformation. Shanghai: Fudan University Press.

Fairbank K. J. 2008. The United States and China (translated by Zhang L. J.). Beijing: World Knowledge Press.

Fei X. T. 2001. Peasant life in China. Shanghai: The Commercial Press.

Gong G. 2001. "The development of markets in North China in modern Chinese history." Modern Chinese History Studies 1:141-167.

He S. Y. 2011. Probing socio-cultural anthropology.Beijing: China Social Sciences Press.

Huan P. Q. 2005. The changing of rural periodic market and transformation of rural social structure in North China: a case study in Ting Hsien (Dingzhou). Ph.D. Dissertation, Renmin University of China.

Huan P. Q. 2016. "Rural market change, social transformation and rural construction in North China: a case study in Ting Hsien (Dingzhou)." Social Construction 5:1-13.

Huang Z. Z. 1986. The Peasant Economy and Social Change in North China. Beijing: Zhonghua Book Company.

Jiang Y. L. 2009. The economic and cultural life of the Pai-I. Kunming:Yunnan People's Publishing House.

Jin B. H. 2007. Policies of Nationalities. Beijing: Minzu University of China Press.

Kato F. 1973. "Regular markets in the villages and towns of the Qing Dynasty." $A$ Research on Chinese Economic History (volume 3)(translated by Wu J.). Shanghai: The Commercial Press. 
Li J. F. 2011. "Ethnic Interaction and National Identity in the Cross-border Trade between China and Vietnam-Taking the market of the people on northwest border in Yunnan Province as an example." Study of Ethnics in Guangxi 4:47-50.

Li Y. Y. 2014. The economy in the area blended by Han-yi. Kunming:Yunnan People's Publishing House.

Li Z. H. 1998. Rural market and modern society: a study on the markets of Villages in North China in the First Half of the 20th Century. Beijing: Contemporary China Publishing House.

Liu S. H. 2010. "Market and modernity in Nuosu (Yi) Area, Southwest China." Thinking 1:22-17.

Liu Y. H. 1993. "Traditional marketing and social structurer in China: a reflection on Skinner's marketing theory and macro regional theory."Researches in Chinese Economic History 4:133-139..

Lu Y. L. 2012. "Examing the development of rural markets from the changes of village markets: Taking Dingzhou Temple Fair in Hebei Province as an example."Jianghai Academic Journal 3:113-121.

Ma X. D. 1987. “Ancient urban and rural markets in Yunnan.”Inquiry into Economic Issues 6:50-53.

Merton. R. 2006. Social theory and social structure (translated by Tang S.J., Qi X.). Nanjing: Yilin Press.

Niu H. B., Wang W. C. 2000. Marketing in Yunnan. Kunming: The Nationalities Publishing House of Yunnan.

Skinner, G. William. 1998. Marketing and social structure in rural China (translated by Shi J. Y., Xu X. L.).Beijing:China Social Sciences Press.

Wan H. 2004. "On the historical formation of the market in southwest minority areas."Guizhou Ethnic Studies 3:100-106.

Wan H. 2006. Studies of the ethnicmarkest in Southwest China.Beijing: China Economic Publishing House.

Wang D. 1993. Stepping out of a closed world--- a study of regional society in the upper Yangtze River (1644-1911). Beijing: Zhonghua Book Company.

Wang Q. C. 2004. "Markets and market circles in North China in the late Qing Dynasty." Modern Chinese History Studies 4:2-69.

Wang Q. C. 2005. "An analysis of the growth of the regular markets in North China in the late Qing Dynasty." Modern Chinese History Studies 6:1-38.

Wang X. Y. 2012. "The construction of border market and village community-based on the investigation of Zhenjiang Town on the Sino-Myanmar Border."Minzu Tribune 4:69-73.

Wu X. Y. 2008. Market politics: the power and integration during exchange. Beijing:China Social Sciences Press.

Xu T. 1998. The development of commodity economy in Shandong Province during Ming and Qing Dynasties. Beijing: China Social Sciences Press.

Yang C. K. 1934. "A Study of Periodic Markets in Chowping Hsien.” Master Thesis, Department of Sociology, Peking University.

Yang M. C. 2001. A Chinese Village, Toutai, Shandong Province. Nanjing: Jiangsu People Publishing LTD.

Yuan Y. X. 2017. Private life under socialism: love, intimacy and family change in a Chinese village, 1949-1999 (translated by Gong X. X.). Shanghai: Shanghai People's Publishing House.

Zhang H., Gu J. R. 2012. "A study of social interaction and the national identity of the People on Yunnan and Myanmar border.” Journal of Yunnan University of Nationalities (Social Sciences) 1:17-22.

Zhang Y., Wang X. Y. 2010. "An analysis of cultural connotation of markets in minority areas-taking Yi people's marketing in Tanhua." Thinking 6:122-126. 